\title{
Gender and Educational Differences in Perception of Domestic Violence against Women amongst Libyan Migrants in Manchester
}

\section{Abstract:}

Domestic violence against women (DVAW) is a worldwide phenomenon and refers to any act committed against women that results in physical and psychological harm, and coercion, loss of liberty, and deprivation. There is a dearth of research and information about the extent and prevalence of domestic violence among Libyan communities. The aim of the study was to explore community knowledge of, and attitudes toward, DVAW and to improve our understanding of the factors that influence knowledge, attitudes, and responses, particularly educational and gender differences. Using snowball sampling, we analysed 20 semi structured interviews with Libyans living in Manchester, United Kingdom. We found gender and education-influenced participants' perception of DVAW. Men in general did not recognize DVAW as a serious social problem; noticeably, they saw it as a personal and family issue. Knowing attitudes toward DVAW is necessary for government and communities' prevention policies as attitudes influence perpetration of DVAW.

Keywords: perceptions of domestic violence, domestic violence, domestic violence and cultural contexts, Islam, patriarchy, gender

Domestic violence against women (DVAW) is an issue in a marital or other intimate relationship (Hearn \& McKie, 2010, Slabbert, 2017), sometimes termed 'wife abuse' or 'wife battering'(DeKeseredy \& Hinch, 1991; Hague \& Malos, 2005). However, it is worth noting that some researchers have distinguished between domestic violence and intimate partner violence, which is physical, sexual, or psychological harm against the other spouse or partner either by a current or former intimate partner (Flasch et al., 2017; Larsen, 2016; Mitchell, 2009; Yalch et al., 2017). This study adopts the UK government's definition of domestic violence which states;

Any incident or pattern of incidents of controlling, coercive, threatening behaviour, violence or abuse between those aged 16 or over who are, or have been, intimate 
partners or family members regardless of gender or sexuality. The abuse can encompass, but is not limited to: psychological, physical, sexual, financial, emotional (UK.Gov, 2013).

DVAW is a worldwide problem. In a study of perception of DVAW in the European Union (EU), $78 \%$ of Europeans acknowledged that domestic violence is commonplace, with one in four respondents knew a women victim of domestic violence (Eurobarometer, 2010). Fifteen percent of respondents across the EU felt that DVAW is a private matter and a concern for family to deal with; this view is prevalent in Eastern Europe (Eurobarometer, 2016). In England and Wales $8.5 \%$ of women and $4.5 \%$ of men reported domestic abuse (Crime Survey of England and Wales [CSEW], 2014).

Factors associated with DVAW among migrant women include language barriers, uncertain legal status, migration laws, availability and accessibility to resources and economic support (McWilliams \& Yarnell, 2013). Migrant women may not report or seek help because culturally, they perceive DVAW as a family issue (Belur, 2008; Condon et al., 2011), and shame and honour influence the acknowledgement and reporting of violence (Belur, 2008; Thiara \& Gill, 2010). The primary help and support offered for abused migrant women comes mainly from female family and friends within their communities (Dutton et al., 2000). However, women in migrant communities often ignore the abuse (Morash et al., 2000; Supriya, 2002), and they are often geographically distant from their families and friends (Bauer et al., 2000). Although some South Asian migrant women in the UK do not have their own family close by, they might live with or close to their husband's family due to cultural rules and economic necessity (Bauer et al., 2000). This might provide support for DVAW, but also would increase the likelihood of abuse from the extended family members (Hopscotch, 2012; Morash et al., 2000; Rehman et al., 2013; Supriya, 2002). Migrant women may be almost wholly dependent on their husbands as their main link to the world outside their homes (Kulwicki et 
al., 2015). These women are vulnerable to DVAW because many of them depend on their husbands for information regarding their legal status (McWilliams \& Yarnell, 2013). A woman's emotional dependence on her husband is also more apparent when she lacks family and other support systems and finds herself lonely in an unfamiliar country. These situations give men increased power and control over wives which can escalate to abuse (Wellock, 2010). Black and minority women including Asians, Middle Easterns, and North Africans experience greater rates of violence, male domination and control, and stay longer in abusive relationships compared to other women in the population (Condon et al., 2011).

The aims of this exploratory study are, first, to explore the perception of domestic violence against women from the point of view of Libyans living in Manchester, United Kingdom, and second, to explore gender and education differences in the perception of domestic violence. Focusing on attitudes towards violence against women is important for primary prevention and monitoring progress (Powell \& Webster, 2016). Therefore, understanding ethnic minority communities attitudes towards violence against women could evolve into an important instrument both for monitoring shifts in knowledge and attitudes, as well as informing primary prevention efforts.

\section{Gender Regimes in Muslim/Arab Communities}

Patriarchy is the primary cause of women's subordination globally (Walby, 1990; Gosselin, 2010; Haj-Yahia et al., 2012; Heise, 2011), and the origin of domestic violence against women is to be found in gender stratification (Dobash \& Dobash, 1979; Hunnicutt, 2009). Arab societies are no exception; gender inequality exists in socio-economic, law, and political spheres (Moghadam, 2004). In most Arab societies including Libya, the right of men to control and chastise women is accepted, justified and legalised (Abu-Hilal \& Al-Hussain, 1997; Gharaibeh \& Al-Ma'aitah, 2002; Haj-Yahya \& Zaatut, 2015). Therefore, the husband is culturally the central authority, to whom the wife and children must ultimately respond 
(Barakat, 1993; Haj-Yahia et al., 2002; Haj-Yahia, 2011; Joseph, 1993). Barakat (1993, p.100) explains that "the traditional Arab father has authority and responsibility, expects respect and unquestioning compliance", and that men maintain their power by control over land, resources (property rights) and income.

However, we believe that patriarchy alone is not the cause of women's oppression in Arab societies, and that this might be related to social conservatism (Kulwicki et al., 2015; Kposowa \& Aly Ezzat, 2016) underpinned by "the belief the that society is built upon a fragile network of relationships, which need to be upheld through duty, traditional values and established institutions" (Heywood, 2017, p. 65). Large segments of Arab Societies support the control of women by means of force, which has its roots in pre-Islamic tribal and Bedouin culture (Ahmed, 1992). Force and the use of power in this respect are not considered abuse, rather such acts are perceived as corrective measures (Joseph, 1996). At the heart of this notion lies the fact that women are like minors and must be punished by their husbands, fathers, and brothers when they are disobedient, and are socialized to accept it (Baloyi, 2013). Socio-cultural and religious practices consider men as powerful and authoritative and women as inferiors and less powerful within Libyan communities. Cultural and societal norms see women as 'impure' and allow men to dominate women. The hijab according to both cultural and religious norms acts as a social institution that safeguards woman's sexuality (Medina, 2014).

Islam has a strong impact on every aspect of society, including definitions of gender roles, the status of men and women in general, and family life and marital relations in particular (Moghadam, 2004; Niu \& Joe Laidler, 2015). In this connection, Islam emphasises the complementary attributes of women and men and dictates their roles accordingly (Joseph, 1993, 1996). Women depend on men to safeguard them and to ensure that men maintain high moral standards. In this spirit, the Qur'an teaches that men and women are companions and are to treat each other with affection and compassion within the bond of matrimony (Stowasser, 1993). 
God says in the Qur'an (30:21), “and among His Signs is this, that He created for you mates from among yourselves, that you may dwell in tranquillity with them, and He has put love and mercy between your hearts: verily in that are Signs for those who reflect”. However, the Qur'an also includes passages, which clearly indicate that obedience and respect for husbands is the Muslim wife's duty (Verse 4:34 of the Qur'an). Some men have tried to justify domestic violence by misinterpreting the aforementioned Verse when states;

Men are the protectors and maintainers of women, because Allah has given the one more strength than the other, and because they support them from their means. Therefore the righteous women are devoutly obedient, and guard what Allah would have them guard. As to those women on whose part ye fear disloyalty and illconduct, admonish them first, next, refuse to share their beds, and last beat them lightly; but if they return to obedience, seek not against them means of annoyance: For Allah is Most High.

According to commentators, the Arabic word, which refers to beating, has different meanings. The use of the word is symbolic, and not meant to inflict harm (Hamid, 2015). Domestic violence exists in Muslim communities but has nothing to do with teachings of Islam, which promotes peace and harmony and forbids violence, except for self-defence (Salamati et al., 2015). Some scholars have deep concerns about the misinterpretation of Islam and the tendency to rectify this impression by saying that “true Islam is against the violation of women's rights and is the religion of peace" (Begikhani et al., 2015, p. 90). Nevertheless, the problem is that other scholars argue for literally interpretation of Qur'anic verses and firm adherence to Sunnah (teaching, sayings, and practices of the Prophet Muhammad) whilst regarding any attempt at modern reinterpretation of Qur'an as bid'ah (religious innovation) (Joppke \& Torpey, 2013). 
Within patriarchal societies, violence against women is justified if their perceived behaviour differs from established local norms (Schuler, et al., 2011). Violence takes place within a moral order in which the victim, perpetrator, and others inhabit (Fiske \& Rai, 2015). Perpetrators activate culturally significant and normative repertoires to rationalize abuse, hold victims responsible, and handle their moral responsibility; victims view wife abuse as "normal, acceptable, disciplinary, and corrective" (Adjei, 2015, p. 1).

In the Middle East and North African countries (MENA), most incidents of DVAW are not openly visible, as people do not report it because it is considered a private matter rather than a social problem (Pargeter, 2010; Haj-Yahya et al., 2012; Kulwicki et al., 2015). The mechanisms of dealing with violence are not effective, due to religious, legal and cultural factors, which maintain and support men's dominance and control over women (Pargeter, 2010). Most MENA countries, including Libya, do not have legislation in place to protect women from domestic violence. The typical religious interpretations and understanding of Islamic scriptures allows men to 'correct' women when this is 'required'. Women rarely contact authorities to register a complaint due to fear of divorce, which brings shame upon them and their families. In addition, women face discrimination by the judiciary. Consequently, many women who face violence feel trapped, incapacitated and helpless, and they have to continue living in the same hostile environment. In the context of migration, specific factors make women's experiences of DVAW unique to the rest of the population. Migrant women's experiences interact in powerful ways with broader factors, such as class, race, language barriers, isolation, economic changes, legal status, and ethnicity (Rehman et. al 2013; Thiara \& Gill, 2010).

\section{Method}

We selected the participants using a snowball-sampling technique. We conducted faceto-face semi-structured interviews with 20 individuals, 13 women and 7 men. Four females in 
the sample were members of the Libyan Women association (LWA) in Manchester. After attending two meetings organised by LWA, we managed to find a further nine participants, which included postgraduate students, doctors, charity members, homemakers, single and divorced women. We found the male participants through recommendation by either friends or colleagues, and their wives. We made initial contacts with two participants who then suggested other individuals who could be willing to participate in the study. This method is useful when it is difficult to identify individuals in the population (Robson, 2002). The age of the thirteen women who participated in the study ranged from 31-54 with the mean and median age being 41 years, all living in Manchester. Seven women were married, five were divorced and one was single. The majority of married and divorced women had migrated to the UK soon after marriage in order to join their husbands, who were either studying, working or were asylum seekers in the UK and were, in the main, permanent residents. One woman, however, came to the UK for educational purposes and was residing temporarily in the UK as she received funding from the Libyan government. In addition, a divorced woman had arrived with her children in the UK as an asylum seeker herself and she was permanently resident. In terms of educational background, five women graduated from secondary school and six women had a Bachelor's degree, two women had only primary school level education. Two women had been in the UK for two years, whilst five women had lived in the UK for 9-12 years and six women had been in the UK for 17-24 years. All the women in this study wore the hijab, the traditional head cover worn by Muslim women; one woman wore the niqab, the face covering which leaves only the eyes visible.

At the time of the interviews, men aged between 33-49 years of age, with the mean and median age being 39 years. Three men had finished high school level prior to migrating, two men had gained a Master's degree and one had attained a $\mathrm{PhD}$. Three of the seven men were single, whilst four were married. Two men resided temporarily in the UK and five were 
permanent residents. Five participants were from the middle class in Libya, whilst one man considered himself upper class because of owning a business and possessing a large house in the UK and in Libya. Only one man considered himself working-class.

\section{Interview Protocol}

When researching attitudes towards DVAW, we must consider participants experiences within multiple influences such as culture, personal values, beliefs, social, economic, and political contexts (Ramazanoglu \& Holland, 2002). Most participants rejected the use of the tape recorder. One woman reported that she had not asked her husband's permission to record the interview. In Libyan culture, women must avoid speaking in public; therefore, some participants did not want their interviews recorded. Therefore, no tape recorder was used, as most of the respondents in the sample did not feel comfortable being audiotaped. This meant we took notes during the interview where possible. However, due to the sensitivities of time and sometimes of place, and as note taking can interrupt the natural flow of a conversation, we wrote them down as soon as possible afterwards. The conversational and easy atmosphere of the semi-structured interviews encouraged women to talk openly about their personal experience.

The semi-structured interviews took place over a period of six months between October 2012 and April 2013. We conducted the interviews in Arabic, and presented the participants with information about the interview and allowed them to ask questions, informing them that they could withdraw from the interview at any time, and then followed by asking them to sign the consent form. We subsequently conducted semi-structured interviews at convenient dates, times and places. The semi-structured interviews with women took place in many venues. Some were in women's houses, at the university, some were in a mosque and coffee shops. The semi-structured interviews lasted, on average, one and a half hours each, with individual interviews ranging from around 45 minutes to three hours, at the end of each interview, the 
informants were debriefed. The most important factor in producing accurate data on DVAW through interviews, is the quality of the interaction between the interviewer and interviewee and, in particular, the ability of the interviewer to infuse a sense of 'trust, safety and intimacy' into the interviewing relationship is important (Brush, 1990). Being a Libyan women gave the co-author of this paper an opportunity to develop a relationship of trust with the women in order to explore and understand their views regarding DVAW. Ribbens \& Edwards (1998) and Merriam et al. (2001) described that some factors, such as culture, class, social status, race, age, can play a major role in facilitating the relationship between researchers and the participants. We have used fictional names to protect the identity of the participants. This study was approved by the ethics review board of Manchester Metropolitan University.

\section{Findings}

\section{Men in the Sample: Understandings of Domestic Violence Against Women}

There were some differences between men and women in relation to their perception of DVAW. Most women in the sample discussed different aspects of DVAW more enthusiastically, and believed this topic to be more relevant to them than did men. By contrast, men in the sample spoke less about DVAW compared with women whilst men approached the topic more in general terms, women's viewpoints were more specific and detailed, as they believed the topic applied to themselves and their lives. Some men interviewed (particularly those with low levels of education) felt uncomfortable at times talking about DVAW, considered talking about this as a matter for women and not for men. Some men in the sample with higher levels of education, however, had knowledge of the topic of DVAW and could talk about this issue. The fact that some had knowledge about DVAW did not necessarily mean that they supported women's rights or policies against DVAW. Some men simply mentioned types of violence briefly when they declared what DVAW meant to them whilst others avoided the question, said little and moved quickly on to another topic, or else changed the subject. This 
particularly applied to those with lower levels of education. However, other men considered DVAW to be a range of male behaviour that women found to be abusive, and which arose from men's position of power in society. For example, Ali a married 37-year-old male with high school education had been in the UK for 17 years. On the first occasion, that we asked Ali what DVAW meant to him, he commenced talking about women's situation in general and about the role of Libyan women in the family. His response was:

DVAW can be verbal or psychological violence, not just physical violence...In general, any behaviour to force a wife to do anything against her will is violence (Ali, married, aged 37 years).

Ali perceived violence to be more emotional than physical abuse within marriage and explained that verbal abuse meant insulting language; he went on to add that emotional abuse referred to any action in which aggressive or insulting behaviour takes place against women for being female. Nevertheless, when asked about violence in the family of origin, where the abuser is the father, brother or another family member e.g. uncle, he stated that women usually do not complain about this in Libyan communities and this was a family issue and not a matter for public discussion.

Samir was another less-educated male in the sample, who was single and had been in the UK for four years. He perceived DVAW to be a kind of power struggle between men and women. He believed men are in position of power, and that they see themselves as possessing the right to control women. Samir said:

Violence is the use of the power to control other people in general, and DVAW occurs when women have less power, therefore, men use their strength to control women (Samir, single, aged 34 years).

Samir explained that men control women economically and emotionally, and in his opinion, Libyan men used physical violence less than other types of violence. However, he also 
justified violence, stating that women needed men, and because of this need, men acquired the right to control women. In his opinion, some men used their strength at home when they lost their temper. He thought that some women provoked men and provocation led to violence against them. Therefore, based on this perception, some men held negative attitudes concerning DVAW and that gender itself could be a significant predictor of justifying DVAW.

The level of understanding of DVAW varied amongst different groups of men, some welleducated male participants considered DVAW to be a serious crime. An example was Ibrahim, a well-educated man who had lived in the UK for more than thirty years.

Ibrahim stated:

DVAW should be treated as crime. Each man makes a choice to use violence and consequently must take responsibility for his action...Women should go to police and police should help them (Ibrahim, married, aged 49 years).

Ibrahim, however, was the only man in the small sample who considered DVAW to be a criminal act, resulting from men's own beliefs and actions. He believed that DVAW was due to the absence of laws to protect women from abuse. In his opinion, Libyan law does not ensure women's rights and fails to protect abused women. He further said even if the law was in existence it might not be enforced. This exploitation of men's position in society, has given men the right to control and beat women, as well as authority within the family. Under a patriarchal system, men control women and this encourages men to feel stronger through committing violence. Ibrahim acknowledged that the UK law protects women against domestic violence, but the reluctance of women to report DVAW to the relevant authorities because of social and cultural reasons was a problem.

Male participants' knowledge of DVAW did not necessarily mean that they supported women's rights. For instance, Hamdi, another highly educated male, was more aware of the issue of DVAW, and could discuss this in detail. He perceived violence to be a gender-related 
issue and that depriving women of access to education was a factor underpinning DVAW. However, he also believed that women themselves were the cause of their own subordination, that the culture of Libyan society had an impact on women, making them too weak to make decisions about their own lives.

Although some men were aware of DVAW and its consequences, they did not recognise DVAW as a serious social problem. Rather, they saw it as a personal and family issue. Some men in the sample stated that DVAW is an act committed only by the husband. Akram, (36 years old, single with a lower level of education) stated: "DVAW is physical harm and beating by the husband, it is violence from the specific man (the husband)". Akram perceived DVAW to be violence in the private sphere (especially in marriage) as well as at family level. According to him, women in the family did not usually object to the violence perpetrated by brothers and fathers, as women could not do anything about it and they would not report it. In Akram's opinion, this kind of violence was not necessarily a problem in Libyan communities, and he justified this by saying that males in the family, such as the father or brother, beat women for understandable reasons. He added; "In our culture, the brother can beat his sister if she makes a mistake and he most definitely will beat anyone who tries to hurt her". This type of response clearly reflected the tendency of some Libyan men to believe that women in the family should be under their control as they are responsible for the family honour. It is likewise seen as men's responsibility to protect women. Most male participants stated that Libyan culture gives men the right to control women; when society tolerates violence, it becomes a normal aspect of women's lives.

Ali stated:

As Libyans, we believe a wife should obey her husband so when she does not, he can beat her. A father and the brother can beat his daughter or sister because we 
need to correct some women, especially if they make mistakes related to family honour (Ali, married, aged 37 years).

In general, many men in this sample believed that, in Libyan communities men perceived their power and privileges, and felt women should know their position. Men expected women in their families to respect them and to obey their rules and attend to their needs.

\section{Women in the Sample: Understandings of Violence Against Women}

Women participants saw DVAW as reflecting gender discrimination and male domination. Some of the women mentioned physical and sexual violence, and some linked DVAW to the deprivation of women's rights. Other women stated a necessity to differentiate between DVAW in cultures such as Libya and the UK, as many acts considered DVAW in the UK would not be in Libya. All women wanted to talk about DVAW; however, the 'better' educated women provided different answers to question about the definition of DVAW compared to 'less' educated women. This clear difference by women's educational level, allowed us to divide perceptions of DVAW into two broad categories: a) DVAW as male domination, and b) physical, sexual, and emotional violence as a family matter.

Less-educated women perceived DVAW to include both physical and emotional abuse but often saw it as a family issue, whilst well-educated women drew attention to gender hierarchical orders that led men to use power to control women. In general, women who participated in this study considered DVAW to be a widespread phenomenon in a Libyan context, some mentioning Libyan society (within Libya) or the Libyan community in the UK. Women believed that domestic violence exists in Libyan communities, verbal and emotional abuse were very common. The rates of violence for less and more highly educated women in the sample were almost equal, but there was a difference in their perceptions and attitudes towards DVAW. For instance, Thuria, a divorced and well-educated woman, aged 46 years who had been in the UK for a long time, stated that DVAW involved lack of understanding of 
women's rights. She mentioned that her ex-husband was well educated but was older than she was, and had not allowed her to work or to go out on her own, she refused to accept this, which led him to be violent. She made it clear that women should speak out about violence and stop treating this as a family matter. Similarly, Salma (married, aged 45), another woman with a high level of education emphasised the lack of understanding of women's rights in Libyan society.

Aisha, another well-educated woman in the sample, talked about sexual harassment in terms of her understanding of DVAW, "rape is also violence and is a very dangerous type of DVAW. This rape could be from a family member not just a stranger and women do not speak about this" (Aisha, divorced, aged 52 years). In addition, insulting and controlling women appeared a very effective way of emotional harm. Hanan, a married well-educated woman, aged 48 years, believed that physical violence is "deliberately hurting or injuring a woman". She said that women in Libyan communities suffer from emotional violence, and women accepted this as part of their lives. She mentioned that men's control of women has complex roots in Libyan communities and the male-dominated underdeveloped society with strong kinship and tribal loyalties that determine the main institution of the family. Some lesseducated women also perceived violence as a part of women's lives, and tended to see this violence as a family issue. They believed that women are socialised to accept and tolerate domestic violence and to remain silent about such experiences, perceiving DVAW as physical violence and the use of physical strength by men. For a female participant DVAW was physical violence at home by any family member:

DVAW is insulting and beating women in the house. This includes hitting, kicking, and hair pulling, beating with objects, throwing and shaking and can cause pain, cuts, and bruising. For Libyan women it is a shameful to speak out about it and 
women will be blaming themselves... but this problem should be treated differently

in Muslim societies (Najah female, married, 36 years of age).

Najah came to the UK with her family before she got married. She did not attend school in England and had completed only secondary school in Libya. She also added that her father was a strict Muslim and he would not allow the girls to attend British schools. Najah did not perceive sexism in her family as inequality or DVAW. She justified it by saying that, because of her father's wish to follow Islamic rules in his way, he did not have any other options to ensure that English culture would not influence the girls.

Karima, another married woman aged 38 years, also with a low educational level, was aware of different views on the subject of DVAW and said that DVAW occurs between individuals and that they can stop it, she went on to say:

Insults, verbal abuse, dominating the whole life of the wife, preventing her from completing her education, and doing unwanted things (sexually) to satisfy the husband is violence. Libyan women suffer from all types of DVAW in both Libya and the UK.

\section{Perceptions of Different Types of DVAW}

The most common patterns of domestic violence included emotional violence such as verbal abuse and negligence. Other forms of DVAW such as economic violence, forced marriage and early marriage also existed in Libyan communities. Several participants talked about other forms of violence, including not allowing women to leave the house, to have access to education, and marrying a second wife (hence, neglecting the first one). The findings show that the participants considered emotional violence to be most common type of DVAW. Verbal abuse was the first frequently mentioned type of violence for participants, followed by economic violence, (general) physical violence, sexual violence, and forced and early marriages respectively. However, some participants did not consider forced and early marriage 
as DVAW because its occurrence is rare in Libyan communities. In total, six women and three men interviewed considered physical violence and sexual abuse to be the most common type of violence occurring in Libyan communities.

There are many types of violence...[in Libya] I knew of a woman's case in which her husband used to abuse her. She had a severe injury by her husband, she was asking for divorce, and she got it. The problem is that some women after a while they go back to their house without any case, or withdrawing the case from the lawyer (Salma, married, aged 45 years).

Some men in the sample also listed acts defined in the literature as emotional and economic abuse more frequently than acts of sexual or physical abuse. Ahmed (well-educated, aged 43), stated that the domestic violence included:

Any behaviour, which results in insulting women, is violence, such as forcing women to keep their voices quiet, preventing her from finishing her study, or from work, shouting at her, forcing her to have sex...Violence in Libya is a problem but we do not talk about it.

Ahmed was in support of women's rights, and held constructive beliefs regarding DVAW. Ahmed criticised the traditional cultural norms in which women are presumed to be passive. However, he admitted in the interview that his wife, who has a BA degree, worked neither in the UK nor in Libya. She looked after the children, as he held down a full-time job and he could provide for his family. This contradiction applies also to other participants. Although many male and female participants said they believed that preventing women from work was one type of violence, when we questioned men if their wives worked, most said they did not (apart from one whose wife works a part time in a Libyan school in the UK). This contradiction could be due to men themselves or women's own decisions. Some women do not work after marriage within Libya communities because working will affect their ability to bring 
up their children. Most women in the sample said that they did not work in Libya and this was their own decision, as they wanted to prioritise motherhood.

\section{Early and Forced Marriage}

Early and forced marriages were amongst the other types of violence discussed by the participants. Some participants considered them as violent actions against women and girls whilst others did not perceive either to be DVAW. In Libya as a rule, marriage is of greater importance than education or employment. According to traditional norms, marriage is the standard whereby a woman's success can be measured (Pargeter, 2010). Therefore, for some early marriage was not a problem for the Libyan community. Nonetheless, some did believe it to be DVAW. For example, Aisha stated that:

Forced marriage...still exists in Libya and I heard that a family forced their girl to get married just to ensure she got a chance to be married. They prefer a girl to live a miserable life rather than to reach her 30s without marriage (Aisha, divorced, aged 52 years).

Aisha was aware of the impact of early marriage on girls' health. In addition, she believed that this was still a problem. She mentioned that many Libyans married at an early age. Aisha added: "I saw many cases suffering from violence because they got married very early ... Some girls get marry when they are 15 years; she is still a child and cannot understand her husband, which leads to violent relationship".

Following the same sentiments, Saeed also saw forced marriage and early marriage as one type of DVAW. He said; "early marriage is DVAW, and some people do it by cheating the law, they change the girl's age to make her in this kind of marriage" (Saeed, married, aged 41 years).

By contrast, other participants did not consider early and forced marriage as DVAW. One male in the sample saw this as a problem that no longer exists in some large Libyan cities such 
as Tripoli. He explained that growing access to the media have influenced social and cultural attitudes, leading people to choice marriages, despite the fact that arranged marriages still exist many men choose the woman they want to marry. Hamdi stated that:

Delaying the age of marriage could be a problem more than early marriage in Libya. I do not think early marriage is violence; my mother and all her sisters got married when they were 15 or 16, they were happy and never complained (Hamdi, single, aged 33 years).

Salma, one of the women interviewed did not perceive early marriage as a form of DVAW. She and her sister were married at an early age. Salma got married when she was 15years-old and still at secondary school. She believed that if a woman was able to bear the responsibility, there was no problem as one of her friends had permitted her 17 years old daughter to marry. Fatima was another woman who also did not perceive early marriage to be DVAW, but did regard forced marriage to be. She said:

I believe that early marriage is not violence, and now in Libyan communities is not very common. In my time (30 years ago), we tended to get marry earlier than now. Forced marriage is still common in rural towns or villages in Libya (Fatima, married, aged 54 years).

Fatima believed that delay of marriage is a big concern for Libyan women. In Libya, the acceptable age for marriage is below 30 for women.

\section{Generational Differences in the Perception of Domestic Violence}

Participants in this smple who were aged less than 40 years tended to mention mental cruelty, verbal abuse, and sexual abuse more than the over $40 \mathrm{~s}$. The results indicate that those who were aged more than 40 years felt that boys who witness their father's violence towards mothers are more likely to become violent when they grow up. These findings might point to generational differences in attitudes. The younger participants largely felt that the key social 
and cultural reasons for DVAW were; lack of education for women, misinterpretation of religious texts, low educational level of men, and women who are highly educated are more likely to suffer violence against them.

\section{Discussion}

The first dimension of the participants' perspectives in understanding perceptions of DVAW in the Libyan community concern definitions. Analysis of the responses revealed that most definitions given, referred to acts which are classified in literature as verbal, emotional, and physical abuse (Buzawa, \& Buzawa, 2002). The majority of respondents declared that DVAW included both physical and emotional abuse (Hague \& Malos, 2005), whilst others drew attention to other dimensions of violence, which included material deprivation and not allowing wives to have access to education or be able to undertake work outside the home (Sanders, 2015). However, the perception of DVAW as a corrective measure is significant, because moral views of offenders are fundamentally in harmony with the opinions and beliefs of their cultural communities (Fiske \& Rai, 2015).

For some men, women accepted DAWA in Libyan communities because they perceived it as a family issue, opposing any involvement from outside bodies (Haj-Yahia, 2005, 2012; Kulwicki et al., 2015; Wu, et al., 2013). Consequently tolerance regarding wife beating continues to exist (Haj-Yahia, et al., 2012). Some well-educated women in the sample who had spent a long time in the UK mentioned that DVAW in Libyan communities

remains one of the most under-reported issues. A patriarchal system appeared, in the views of the participants, to provide a general context for DVAW. However, societal norms, particularly patriarchal beliefs and women's subordination to men alone cannot explain women's tolerance and acceptance of DAWA. Social conservatism, which is located at the intersection of patriarchy, culture, societal norms, and misinterpretation of religious texts, 
could provide a better explanation. The recognition of DVAW indicates that they do not necessarily believe it is always justified.

Early and forced marriage were seen by some participants as DVAW whilst others did not, and felt that this is no longer the case in large cities as some women choose to complete their education. In addition, many men in Libya tend to marry when they are older, because they must be able to support a wife. Many Libyan men have low salaries and there are limited employment opportunities. As a result, many men, especially those from low-income families, do not achieve the requisite level of stability until they are in their 30s (Pargeter, 2010). In Libya, women are legally empowered to negotiate their marriages, but the cultural norms reduce their ability in practice. For example, cultural norms and traditions dictate that a woman should obtain the consent of her father or male guardian before she marries. Based on the participants' accounts, early marriage is generally less serious and less prevalent than other forms of violence within the sample. Thus, there is a tendency to normalise early marriage (Dobash \& Dobash, 1979; Haj-Yahia, 2005).

Men in this sample indicated that males had no right to commit 'physical violence' against women under any circumstances. Nevertheless, contradictions appeared later in the testimony of several male participants, who, on occasion, found or cited cases where DVAW could be justified. When it came to real-life situations, they converted to monitoring, control, coercion, and violence if a woman crossed the 'limits' set by her husband.

Furthermore, the participants' testimonies indicated that long residence in the UK could have an impact on Libyans with regard to DVAW. Whilst a few of the participants - mainly men - mentioned that their attitudes towards DVAW had not been altered, several women in this sample declared that British culture had influenced them. In addition, women's testimonies in this sample, indicated that migrant women were more likely to report violence than women in Libya, and some women in this sample had accessed UK law when they 
obtained their divorces. However, a deeper analysis of the findings indicated that persistence of patriarchy existed among this sample, and migration might not substantially affect views on women's subordination and gender equality.

There was awareness of the avenues of support that could be accessed by women experiencing DVAW, and a number of abused women did seek help from the different sources of support available in the UK. All participants believed that support and protection for abused women in Libya comes mainly from the family.

\section{Conclusion}

DVAW is a global problem and affects all nations and groups around the world. The aim of this study was to explore the attitudes and perception of a sample of Libyans living in Manchester, United Kingdom. Semi-structured interviews were used to collect data. Women talked more in detail about DVAW; however, women did differ to some extent amongst themselves in how they perceived DVAW. Differences in education, for example. Some lesseducated men tended to be less aware of DVAW.

Some women mentioned that DVAW included both physical and emotional abuse whilst others drew attention to other dimensions of violence including material deprivation, sexual abuse and not allowing wives to have access to education or work outside the home. Some less-educated women perceived violence to be solely a 'family issue'. Men tended to downplay discussion of types of DVAW and spoke of this very briefly. Some men with low levels of education were inclined to perceive DVAW as a personal issue. Likewise, some participants considered early and forced marriage less common types of DVAW than other forms of violence.

In studying Libyan communities, one must consider the context of religion. Islam constitutes the fundamental sociocultural and organisational background for most Libyan people. Islam mainly emphasises the complementary attributes of gender, and dictates gender 
roles and relations accordingly (Stowasser, 1993). The community relations of Libyan migrants are also of much importance. Although Libyan migrants may find themselves living in a less traditional society, social conservatism still shapes their attitudes to gender relations. Religion and social norms, patriarchy, culture, and ties with the country of origin intersect and continue to play an important role in determining Libyans' attitudes towards DVAW. The wider family plays an important role in supporting women, and continue to influence Libyan migrants. Family continues to be a central unit in Arab/Muslim societies, and continue to play an important role in supplementing assistance received from formal services (Barakat, 1993). Support and protection for abused women would come mainly from the family (Barakat, 1993; Haj-yahia, 2000). Thus, family is a key element in persistence of patriarchal relation. Families and communities may also turn 'inwards' for protection in new settings and may strongly police patriarchal gendered roles within the migrant families as a way of ensuring cultural continuity (Abraham, 1998). Western acculturation and assimilation can diminish tolerance for violence against women (Bui, 2005). Accordingly, the perceptions of wife beating as a corrective measure maybe be attributed to the socio-cultural and religious contexts of Libyan society. Specifically, these perceptions have not resulted from contact with Western culture and exposure to gendered violence discourse. Considering the results, it would be valuable to conduct future research among Libyans and other Muslim communities in Western societies.

\section{Limitations}

We have explored educational and gender differences in participants' perceptions of DVAW, and made some attempt at comparing generational differences. We are aware of the fact that the experience of migration and length of residence in the host country have influenced participants' perception to some extent. However, there is a need for more research into women's actual experience of violence, including emotional and verbal abuse, and justification 
of violence. We have no intention to generalize our findings from this particular study. We are also conscious that some participants might have given socially desirable answers, which are not necessary reflective of their true feelings. The age range of the participants in the sample is not wide enough to warrant a definite conclusion on age differences affecting perception of DVAW.

\section{Implications}

Attitudes to DVAW are not the whole story. They do not tell us much about the actual experiences of violence, they are however, important (VicHealth, 2010). They assist us in expressing how we perceive situations, and how we act toward the situation. Understanding attitudes towards DVAW is crucial for prevention strategies, as attitudes shape perpetration of DVAW, women's reactions to victimisation as well as community and institutional responses (Flood \& Pease, 2006). Intervention programs must become more culturally relevant and devoid of bias and prejudice, and to consider the role of family and religion in the life of Libyan women in order to develop community wide prevention programs.

\section{Statement of Diversity}

In the process of conducting our research, we have been truly committed to equality for all human beings, regardless of country of origin, religion, race, age, colour, sex, sexual orientation, language and socioeconomic status. 


\section{References}

Abraham, M. (1998). Speaking the unspeakable: Marital violence against South Asian immigrant women in the United States. Indian Journal of Gender Studies, 5 (2), 215 241.

Abu-Hilal, M. M. \& Aal-Hussain, A. A. (1997). Dimensionality and Hierarchy of the SDQ in a Non-Western Milieu: A Test of Self-concept Invariance across Gender. Journal of Cross-Cultural Psychology, Vol. 28 (5), 535-553.

Adjei, S. B. (2015). Correcting an Erring Wife Is Normal” : Moral Discourses of Spousal Violence in Ghana. Journal of Interpersonal Violence. 1-22. DOi 08862605619751

Ahmed, L. (1992). Women and Gender in Islam. New Haven and London: Yale University Press.

Baloyi, M.E. (2013). Wife beating amongst Africans as a challenge to pastoral care. In die Skriflig/In Luce Verbi; 47 (1). 10 pages. doi: 10.4102/ids.v47i1.713. 
Barakat, H. (1993). The Arab world: Society, culture and state. California: University of California. Berkeley.

Bauer, H. M, Rodriguez, M. A, Quiroga, S. S., \& Flores-Ortiz, Y. G. (2000). Barriers to health care for abused Latina and Asian immigrant women. Journal of Health Care for the Poor and Underserved, 11(1), 33-44.

Begikhani, N., Gill, A. K., \& Hague, G. (2015). Honour-based violence-Experiences and counter-strategies in Iraqi Kurdistan and the UK Kurdish Diaspora. London, England: Ashgate.

Belur, J. (2008). Is policing domestic violence institutionally racist? A case study of south Asian Women. Journal of Policing and Society: An International Journal of Research and Policy, 18 (24), 426-444.

Brush, L.D. (1990). Violent acts and injurious outcomes in married couples: Methodological issues in the national survey of families and households. Gender and Society, 4 (1), $56-67$.

Bui, H. (2005). Perceptions of intimate violence and attitudes toward interventions. Journal of Ethnicity in Criminal Justice, 3(4), 1-27.

Buzawa, E. S., \& Buzawa, C. G. (2002). Domestic violence: The Criminal Justice Response. London: Sage.

Condon, S., Lisse, M., \& Schrottle, M. (2011). What do we know about gendered violence and ethnicity across Europe? In Thiara, R., Condon, S. \& Schroettle, M. (eds) Violence against women and ethnicity: Communalities and differences across Europe (pp. 59-76). Berlin. Barbara Buarich.

CSEW. (2014). Violent crime and sexual offences - Intimate personal violence and serious sexual assault. [Online] Available at: 
http://webarchive.nationalarchives.gov.uk/20160105160709/http://www.ons.gov.uk/o ns/dcp171776_394500.pdf. [Accessed: 5 January 2017].

DeKeseredy, W. S., \& Hinch, R. (1991). Woman abuse: Sociological perspectives. Toronto. Thompson Educational Publishing.

Dobash, R. E., \& Dobash, R. P. (1979). Violence against wives: A case against the patriarchy. New York: The Free Press.

Dutton, M., Orloff, L. E., \& Hass, G. A. (2000). Characteristics of help-seeking behaviours, resources, and service needs of battered immigrant Latinas: Legal and policy implications. Georgetown Journal on Poverty Law and Policy, 7, 245-305.

Eurobarometer 344. (2010). Domestic violence against women. [Online] Available at:http://ec.europa.eu/public_opinion/archives/ebs/ebs_344_en.pdf. [Accessed 16 December 2016].

Eurobarometer (2016). Gender based violence Report. Special Eurobarometer 449 Report. Doi:10.2838/009088

Fiske P. A., \& Rai T. S. (2015). Virtuous violence: Hurting and killing to create, sustain, end and honor social relationships. Cambridge, UK: Cambridge University Press.

Flasch, P, Murray. C. E., \& Crowe. A. (2017). Overcoming abuse: A phenomenological investigation of the journey to recovery from past intimate partner violence. Journal of Interpersonal Violence, 32 (22), 3373-3401.

Flood, M., \& Pease, B. (2006). The Factors Influencing Community Attitudes in Relation to Violence against Women: A Critical Review of the Literature. Melbourne: Victorian Health Promotion Foundation [Online] Available at: http://www.vichealth.vic.gov.au/assets/contentFiles/CAS Paper3 CriticalLiterature.p df [Downloaded December 2013]. 
Gharaibeh, M., \& Al-Ma'aitah, R. (2002). The Cultural Meaning of Violence against Women: Jordanian Women's Perspective. Guidance and Counselling, 18 (1): 2-9.

Gosselin, D. K. (2010). Heavy hands: An introduction to the crimes of family violence (4th ed.). Boston, MA: Prentice Hall.

Hague, G., \& Malos, E. (2005). Domestic violence: Action for change. United Kingdom: New Clarion Press.

Haj Yahia, M. M. (2000). Wife-abuse and battering in the sociocultural context of Arab society. Family Process, 39(2), 237-255.

Haj-Yahia, M.M., Musleh, K., \& Haj-Yahia, Y. (2002). The incidence of adolescent maltreatment in Arab society and some of its psychological effects. Journal of Family, $23(8), 1032-1064$.

Haj-Yahia, M. M. (2005). On the characteristics of patriarchal societies, gender inequality, and wife abuse: The case of Palestinian society. Adalah's Newsletter, l (20), 1-6.

Haj-Yahia, M. M. (2011). Contextualizing interventions with battered women in collectivist societies: Issues and controversies. Aggression and Violent Behavior, 16, 331-339.

Haj-Yahia, M. M., Wilson, R. M., \& Naqvi, S. A. M. (2012). Justification, perception of severity and harm, and criminalization of wife abuse in the Palestinian society. Journal of Interpersonal Violence, 27, 1932-1958.

Haj-Yahia, M. M., \& Zaatut, A. (2015).Belief of Palestinian women from Israel about the responsibility and punishment of violent husbands and about helping battered women. Journal of Interpersonal Violence. 1-22. DOI: 0886260515608802.

Hamid, R. M. (2015). Domestic violence in Muslim communities. In A. Johnson (ed.), Religion and men's violence against women (pp 319-342). Springer. New York.

Heise, L. L. (2011). What works to prevent partner violence: An evidence overview. London, England: Strive Research Consortium. 
Hearn, J., \& McKie, L. (2010). Gendered and social hierarchies in problem representation and policy processes: 'DDomestic violence’' in Finland. Violence Against Women, 16, 136-158. doi:10.1177/1077801209355185

Heywood, A. (2017). Political ideologies: An introduction. Palgrave Macmillan.

Hopscotch (2012). Survey of domestic violence within Camden's Asian communities. [Online] Available at: http://www.cscb-new.co.uk/wp-content/uploads/2015/10/Report-of-DVSurvey-2012.pdf.

Hunnicutt, G. (2009). Varieties of patriarchy and violence against women: Resurrecting "patriarchy" as a theoretical tool. Violence Against Women, 15, 553-573.

Joppke, C. \& Torpey, J. (2013). Legal integration of Islam: A transatlantic comparison. Cambridge, Mass. Harvard University Press.

Kulwicki, A., Ballout, S., Kilgore, H. A., Hammad, A., \& Dervartanian, H. (2015). Intimate partner violence, depression, and barriers to service utilization in Arab American women. Journal of Transcultural Nursing, 26, 24-30.

Kposowa, A. J., \& Aly Ezzat. D. (2016). Religiosity, conservatism, and acceptability of antifemale spousal violence in Egypt. DOI: 0886260516660976.

Larsen, M. M. (2016). Health inequities related to intimate partner violence against women: The role of social policy in the United States, Germany, and Norway. Springer International Publishing. Switzerland.

Joseph, S. (1993). Connectivity and patriarchy among urban working class families in Lebanon. Ethos, 21 (4), 452-484.

Joseph, S. (1996). Patriarchy and development in the Arab world. Gender and Development, 4 (2): 14-19. 
McWilliams, N., \& Yarnell, P. (2013). The Protection and Rights of Black and Minority Ethnic Women Experiencing Domestic Violence in Northern Ireland. NICM Report. [Online] Available at: http://uir.ulster.ac.uk/32688/1/BMEWomenDVCEDAWsubmission.pdf. [Accessed 8 January 2017].

Medina, J. (2014). This battlefield called my body: Warring over the Muslim female. Religions, 5, 876-885; doi:10.3390/rel5030876

Merriam, S. B., Johnson-Bailey, J, Lee, M., Kee, Y.,Ntseane, G., \& Muhamad. M. (2001). Power and positionality: Negotiating Insider/outsider status within and across cultures. International Journal of Lifelong Education 20, 405-416.

Mitchell, C. (2009). Intimate partner violence: A health-based perspective. Oxford University Press. Oxford.

Moghadam, V. M. (2004). Towards gender equality in the Arab and Middle East region: Islam, culture, and feminist activism. United Nations Development Programme. Human Development Report Office.

Morash, M., Bui, M., \& Santiago, A. (2000). Gender specific ideology of domestic violence in Mexican origin families. International Review of Victimology, 1, 67-91.

Niu, X., \& Joe Laidler, K. A. (2015). Understanding domestic violence against Muslim women in China. Feminist Criminology, 10(1), $92-112$.

Pargeter, A. (2010). Libya. In Kelly, S., \& Breslin, J. (eds.) Women's rights in the Middle East and North Africa: Progress amid resistance (pp. 283-310). New York, NY: Freedom House; Lanham, MD: Rowman \&Littlefield Publishers.

Powell, A., \& Webster, K. (2016). Cultures of gendered violence: An integrative review of measures of attitudinal support for violence against women. Australian \& New Zealand Journal of Criminology. DOI.10.1177/0004865816675669. 
Ramazanoglu, C., \& Holland, J. (2002). Feminist methodology: Challenges and choices. London: Sage.

Rehman, Y., Kelly, L., \& Siddiqui, H. (2013). Moving in the shadows: Violence in the lives of minority women and children. England. Ashgate publishing limited.

Ribbens, J., \& Edwards, R. (1998). Feminist dilemma in qualitative research: Public knowledge and private lives. London: Sage.

Robson, C. (2002). Real World Research: A Resources for social Scientists and Practitioner Researchers. Oxford: Blackwell.

Salamati, P, Naji, Z., \& Koutlaki, S. A. (2015). Both Islam and Christianity Invite to Tolerance: A Commentary on Dirk Baier. Journal of Interpersonal Violence, 30(20) $3479-3485$.

Sanders. K. C. (2015). Economic Abuse in the Lives of Women Abused by an Intimate Partner: A Qualitative Study. Violence Against Women, 21(1), 3-29.

Schuler S. R., Lenzi R., \& Yount K. M. (2011). Justification of intimate partner violence in rural Bangladesh: What survey questions fail to capture. Studies in Family Planning, $42,21-28$.

Slabbert, I. (2017). Domestic violence and poverty: Some women's experiences. Research on Social Work Practice, 27(2), 223-230.

Stowasser, B. F. (1993). Women's issues in modern Islamic thought. In J. E. Tucker (ed.) Arab women: Old boundaries, new frontiers (pp. 3-28). Indianapolis, IN: Indiana University Press.

Supriya, K. E. (2002). Shame and recovery: Mapping identity in an Asian women's Shelter. New York: Peter Lang Publishing, INC.

Thiara, R., \& Gill, A. (2010). Violence against women in South Asian communities: Issues for policy and practice. London: Jessica Kingsley publisher. 
UK. Gov; https://www.gov.uk/guidance/domestic-violence-and-abuse\#history.

VicHealth (2010). National Survey on Community Attitudes to Violence against Women 2009: Changing Cultures, Changing Attitudes Preventing Violence against Women. Victorian Health Promotion Foundation and Carlton. [Online] Available at: http://www.vichealth.vic.gov.au/ /media/ResourceCentre/PublicationsandResources/P DVAW/NCAS_CommunityAttitudes_report_2010.ashx [Downloaded December 2013].

Walby, S. (1990). Theorising Patriarchy.Oxford: Basil Black Well.

Wellock, V. K. (2010). Domestic abuse: Black and minority-ethnic women's perspectives. Midwifery, 26, 181-188.

Wu, Y., Button, D. M., Smolter, N., \& Poteyeva, M. (2013). Public responses to intimate partner violence: Comparing preferences of Chinese and American college students. Violence and Victims, 28, 303-323.

Yalch, M. M, Alytia, A, Levendosky, N. B, \& Bogat, G. A. (2017). Main and moderating influence of temperament traits on the association between intimate partner violence and trauma symptoms. Journal of Interpersonal Violence, 32 (20), 3131-3148. 